\title{
Reliability of Measuring Thoracic Kyphosis Angle, Lumbar Lordosis Angle and Straight Leg Raise with an Inclinometer
}

\author{
Andrew S. Van Blommestein ${ }^{1}$, Jeremy S. Lewis ${ }^{2,3,4}$, Matthew C. Morrissey ${ }^{5}$, and Sian MacRae ${ }^{1,2, *}$ \\ ${ }^{I}$ Division of Applied Biomedical Research, School of Biomedical and Health Sciences; ${ }^{2}$ Therapy Department, Chelsea \\ and Westminster NHS Foundation Trust, London, UK; and ${ }^{3}$ Physiotherapy Department, St George's Healthcare NHS \\ Trust, London, UK; ${ }^{4}$ Musculoskeletal Services, Central London Community Healthcare, London, UK; ${ }^{5}$ Faculty of Health \\ Sciences, University of Ljubljana, Slovenia
}

\begin{abstract}
Purpose: Several non-invasive measurement methods have been described in the literature for recording thoracic kyphosis, lumbar lordosis and straight leg raise (SLR). However, attempts to quantify the reliability of the inclinometer in these measurements are scarce. In addition, existing reliability studies within the literature were found to use small sample sizes. The aim of this investigation was to examine the intra-rater reliability of the chief investigator $(\mathrm{SM})$, in order to provide clinicians with data that will allow them to better measure sagittal spinal posture and SLR. A blinded test-retest design was performed to determine the intra-rater reliability of thoracic kyphosis, lumbar lordosis and SLR when assessed using an Isomed inclinometer in normals.

Methods. Thirty asymptomatic subjects were assessed on two occasions separated by a time interval of 1 hour to reduce investigator memory bias. Thoracic and lumbar measurements were recorded in a relaxed standing position using an inclinometer; SLR of the dominant leg was assessed with subjects in the supine position. Intraclass correlation coefficients (ICC), 95\% confidence intervals (CI), and standard errors of measurement (SEM) were analysed to determine measurement reliability.

Results. The chief investigator demonstrated excellent intra-rater reliability in the measurements of thoracic kyphosis, lumbar lordosis and SLR. ICC $(2,3)$ values for all three variables exceeded the 0.90 threshold suggesting that the reliability of these measures are acceptable for clinical application.

Conclusions. The inclinometer technique employed in this study to record thoracic kyphosis, lumbar lordosis and SLR is a reliable measurement method.
\end{abstract}

Keywords: Intra-rater reliability, lumbar lordosis, posture, straight leg raise, thoracic kyphosis.

\section{INTRODUCTION}

The evaluation of posture is commonly assessed to help guide diagnosis and plan treatment in musculoskeletal conditions $[1,2]$. Two variables commonly assessed during an examination of spinal posture are thoracic kyphosis and lumbar lordosis. It has been suggested that deviations in one or both of these variables may increase a person's risk of developing low back pain [3-5]. In addition, the straight leg raise (SLR) test, which is used to stress neuromuscular structures, is a potential indicator of lumbar disc pathology [6], often becoming impaired during presentations of low back pain and sciatica [7].

Standing radiographs are the gold standard method for measuring spinal angles. The radiograph enables the traditional Cobb method, modified Cobb method, computer assisted method for deriving radius of thoracic spine curvature, and thoracic vertebral centroid angles to be calculated $[8,9]$. The use of a simple, quick and reliable

*Address correspondence to this author at the Physiotherapy Deparment Chelsea and Westminste Hospital, London SW10 9NH; Tel: 02033158404; Fax: 02033158402; E-mail: sian.macrae@chelwest.nhs.uk method for measuring both spinal angles and SLR would be beneficial in a clinical setting where radiographic investigations are not commonly indicated.

Since its inception in the late 1960's, inclinometry has received widespread attention by many authors who advocate its use in measuring both spinal posture [10-15] and SLR [16, 17]. Non-invasive measurement devices such as the inclinometer may help improve diagnostic accuracy and aid the clinician in determining a patient's progress more efficiently [11].

Despite the inclinometer's increasing popularity, reports detailing its reliability are scarce [15]. The fact that there have been negligible efforts to investigate the reliability of thoracic kyphosis, lumbar lordosis and SLR measurements using this tool in a clinical setting may result in a lack of validity of the outcome measures obtained from its use. Previous inclinometer studies have used small samples sizes $[10,17]$ and less robust reliability statistics [18]. Therefore, an investigation using a larger sample size, supported by appropriate reliability statistics is required. The aim of this study was to investigate the intra-rater reliability of measuring thoracic kyphosis angle, lumbar lordosis angle and SLR using an inclinometer in a clinical environment. 


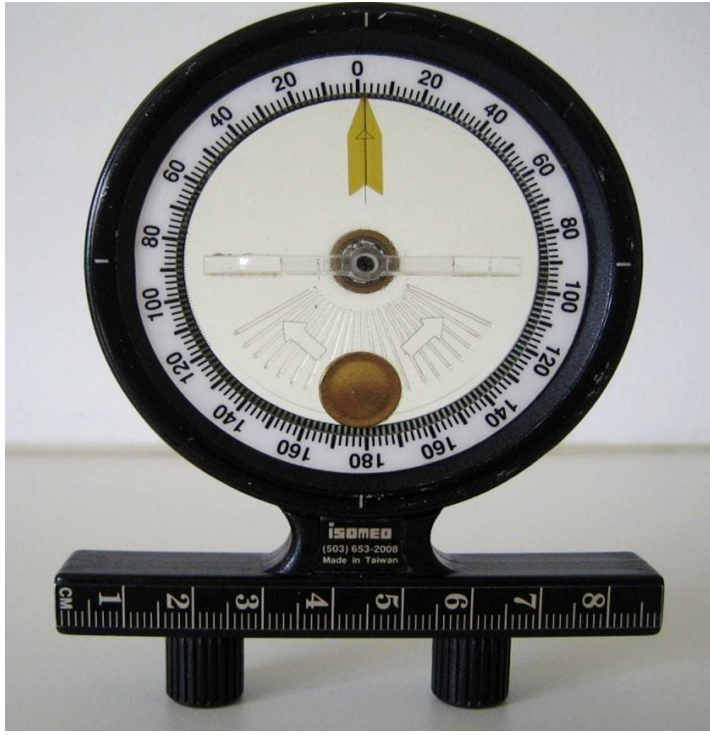

Fig. (1). Isomed Inclinometer.

The experimental hypothesis for this study was that the intrarater reliability of the investigator measuring thoracic kyphosis angle, lumbar lordosis angle and SLR will show acceptable intraclass correlation coefficients (ICC $=0.91-1.00$ ) indicating reliability suitable for clinical measurements [19].

\section{MATERIALS AND METHODS}

\section{Subjects}

This study was approved by a Research Ethics Subcommittee at King's College London [KCL]. Subjects were recruited via email advertising using the KCL website and by verbal invitation at the Guy's Campus at KCL. Male and female volunteers aged 18 to 65 years of age fulfilled the inclusion criteria. Exclusion criteria were any indication of lower limb neurological compromise, or a history of thoracic pain, lumbar pain, or lower limb disorders over the past six months requiring medical attention. Limitation of movement of the hip or knee, scoliosis, chest conditions such as asthma, chronic bronchitis and emphysema, pregnancy, any systemic illness, and an inability to give informed consent were also criteria for exclusion.

\section{Procedure}

All testing was conducted in the same room at KCL by the chief investigator (SM). Those individuals who agreed to participate and met the inclusion criteria and did not fulfil the exclusion criteria were invited to attend two appointments, approximately one hour apart. On the first appointment subjects were given a full explanation of the testing procedure, warned of any potential risk factors and asked to sign informed consent documentation by the second investigator (AVB). Body mass, height and age were recorded.

Prior to measuring spinal angles, participants were asked to stand with their feet either side of a spot marked on the floor (to ensure standardisation of subject position between measures) and adopt a comfortable standing position that felt natural to them. The spinous processes of T1/T2, T12/L1 and $\mathrm{S} 2 / \mathrm{S} 3$ were then identified by palpation and marked with six millimetre diameter non-allergenic adhesive stickers. The

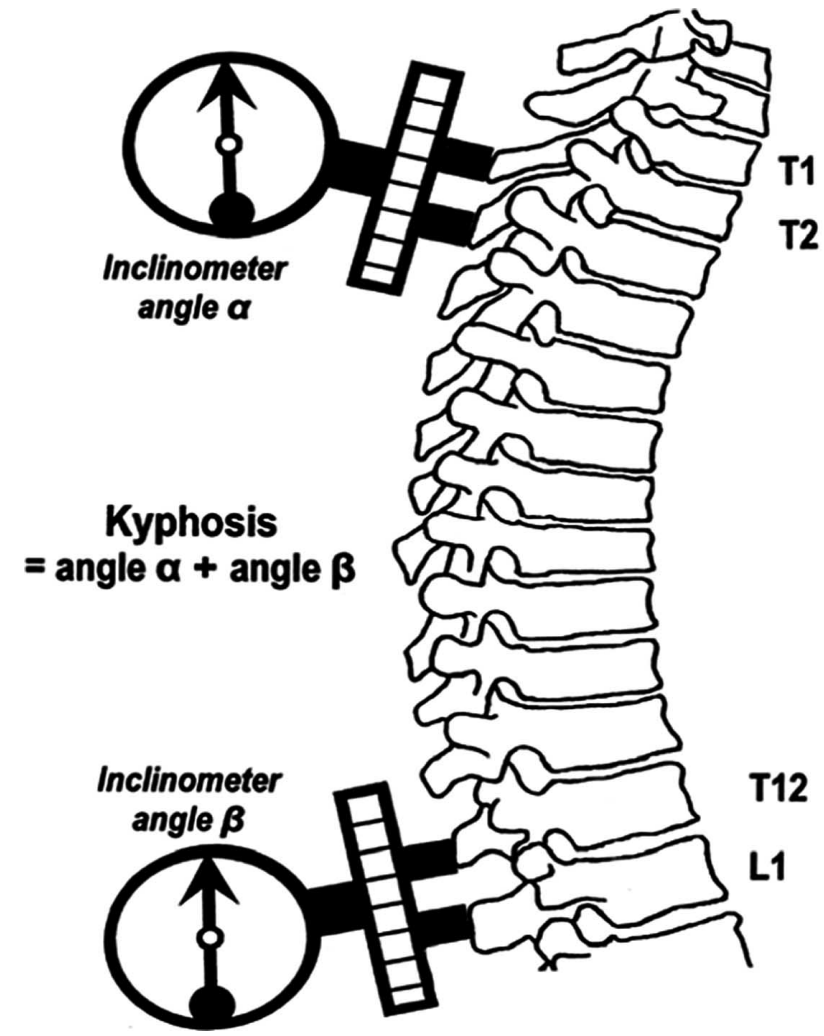

Fig. (2). Angle for measuring thoracic and lumbar spine angles.

palpation techniques employed in this study were adapted from those described by Palastanga et al. [20]. Three inclinometer (Isomed Unilever) measurements (Isomed, 975 Sandy Blvd., Portland, OR 97214) were then taken from each marker location. The inclinometer Fig. (1) consists of a perspex protractor with a freely swinging pointer, and two feet which project from its base. The pointer is gravitydependent and reads the angle tangent to the surface being measured. Mean values were summated, using the linear \& triangular addition of angles rule [12], for T1/T2 and T12/L1 measurements and T12/L1 and S2/S3 measurements to acquire the thoracic kyphosis Fig. (2) and lumbar lordosis angle, respectively.

On completion of the standing measurements, subjects were asked to lie supine on a plinth with a pillow under their head, arms by their sides, no lateral flexion or rotation at their trunk, and hips in neutral adduction/abduction. An adhesive marker was then placed directly on the subject's tibial tuberosity of their dominant [test] leg [determined by asking each subject which leg they would kick a football with]. During the SLR test, the subject's contralateral knee was stabilised by one of the two examiners in an attempt to reduce spinal movement. Three inclinometer readings, representing SLR, were taken by placing the apparatus over the marker [17]. The end point of the SLR movement was determined when the subject reported the first onset of either stretch or discomfort.

All stickers were removed after the first measurement session. The interval between appointments was one hour ensuring that the chief investigator could not recall previous measurements. To further reduce investigator memory bias, the data collection procedure was staggered with two other subject data collections filling the time between another 
Table 1. Subject Demographics

\begin{tabular}{|c|c|}
\hline Variables & Subjects $(\mathbf{n}=\mathbf{3 0})$ \\
\hline \hline Age (years) & $33(\mathrm{SD}+/-11.23)$ \\
\hline Body height $(\mathrm{cm})$ & $172(\mathrm{SD}+/-11)$ \\
\hline Body mass $(\mathrm{kg})$ & $72(\mathrm{SD}+/-12)$ \\
\hline \multirow{2}{*}{ Gender } & Male: $15(50 \%)$ \\
& Female: $15(50 \%)$ \\
\hline \multirow{2}{*}{ Dominant Leg } & Right: $27(90 \%)$ \\
& Left: $3(10 \%)$ \\
\hline
\end{tabular}

subject's first and second visits. This meant that a total of 18 measurements were recorded before the second set of measurements were made on the initial subject.

\section{Sample Size Estimation}

For a significance level of $5 \%$ and a power of 80 , the suggested adequate number of subjects required is 19 [21, 22]. The number of subjects recruited into the current study was increased to 30 in order to increase statistical power, and to account for a loss of subject data and subject withdrawal.

\section{Statistical Analysis}

Mean values of each measurement recorded were used for data analysis. Intra-rater reliability was determined by means of intraclass correlation coefficients (ICC), $95 \%$ confidence intervals $(95 \% \mathrm{CI})$ and standard error of measurements (SEM) [23]. ICC model 2 has been suggested [19] to be best suited for generalizing the findings to clinicians with similar clinical experience. ICC models for single measures $(2,1)$ and for average measures $(2,3)$ were evaluated using SPSS version 17.0 software [SPSS Inc., Chicago, Il, USA]

\section{RESULTS}

A total of 30 asymptomatic subjects ( 15 female, 15 male) were recruited for this study. Subject demographic data is presented in Table 1. The ICC, 95\% CI and SEM for the spinal and SLR measurements are presented in Table 2. The ICC Model $(2,1)$ results for the single measurements ranged

Table 2. Intra-rater Reliability Results

\begin{tabular}{|c|c|c|c|c|}
\hline & & $\begin{array}{c}\text { Thoracic Kyphosis } \\
\text { (T1/2 + T12/L1) }\end{array}$ & $\begin{array}{c}\text { Lumbar Lordosis } \\
\text { (T12/L1 - S2/3) }\end{array}$ & $\begin{array}{c}\text { Straight Leg } \\
\text { Raise }\end{array}$ \\
\hline \multirow{2}{*}{$\begin{array}{c}\text { Mean } \\
\left({ }^{\circ}\right)\end{array}$} & Test 1 & $32(\mathrm{SD}+/-8)$ & $-29(\mathrm{SD}+/-8)$ & $80(\mathrm{SD}+/-12)$ \\
\hline & Test 2 & $33(\mathrm{SD}+/-8.1)$ & $-29(\mathrm{SD}+/-8)$ & $81(\mathrm{SD}+/-12)$ \\
\hline \multirow{2}{*}{$\begin{array}{c}\text { Range } \\
\left({ }^{\circ}\right)\end{array}$} & Test 1 & $17-48$ & $-50-(-14)$ & $59-104$ \\
\hline & Test 2 & $16-48$ & $-52-(-13)$ & $59-105$ \\
\hline \multicolumn{2}{|c|}{$\begin{array}{l}\text { Single Measure } \\
\text { ICC }(2,1)\end{array}$} & 0.92 & 0.79 & 0.94 \\
\hline \multicolumn{2}{|c|}{$\begin{array}{c}95 \% \mathrm{CI} \\
\text { for } \operatorname{ICC}(2,1)\end{array}$} & $0.84-0.96$ & $0.60-0.90$ & $0.88-0.97$ \\
\hline \multicolumn{2}{|c|}{$\begin{array}{c}\operatorname{SEM}\left({ }^{\circ}\right) \\
\text { for } \operatorname{ICC}(2,1)\end{array}$} & 2.3 & 3.8 & 3.0 \\
\hline \multicolumn{2}{|c|}{$\begin{array}{l}2 \times \operatorname{SEM}\left({ }^{\circ}\right) \\
\text { for } \operatorname{ICC}(2,1)\end{array}$} & 4.6 & 7.7 & 5.9 \\
\hline \multicolumn{2}{|c|}{$\begin{array}{l}\text { Average Measures } \\
\operatorname{ICC}(2,3)\end{array}$} & 0.96 & 0.93 & 0.98 \\
\hline \multicolumn{2}{|c|}{$\begin{array}{c}95 \% \mathrm{CI} \\
\text { for } \operatorname{ICC}(2,3)\end{array}$} & $0.92-0.98$ & $0.83-0.97$ & $0.96-0.99$ \\
\hline \multicolumn{2}{|c|}{$\begin{array}{c}\operatorname{SEM}\left({ }^{\circ}\right) \\
\text { for } \operatorname{ICC}(2,3)\end{array}$} & 1.7 & 2.3 & 1.7 \\
\hline \multicolumn{2}{|c|}{$\begin{array}{l}2 \times \operatorname{SEM}\left({ }^{\circ}\right) \\
\text { for } \operatorname{ICC}(2,3)\end{array}$} & 3.3 & 4.6 & 3.5 \\
\hline
\end{tabular}




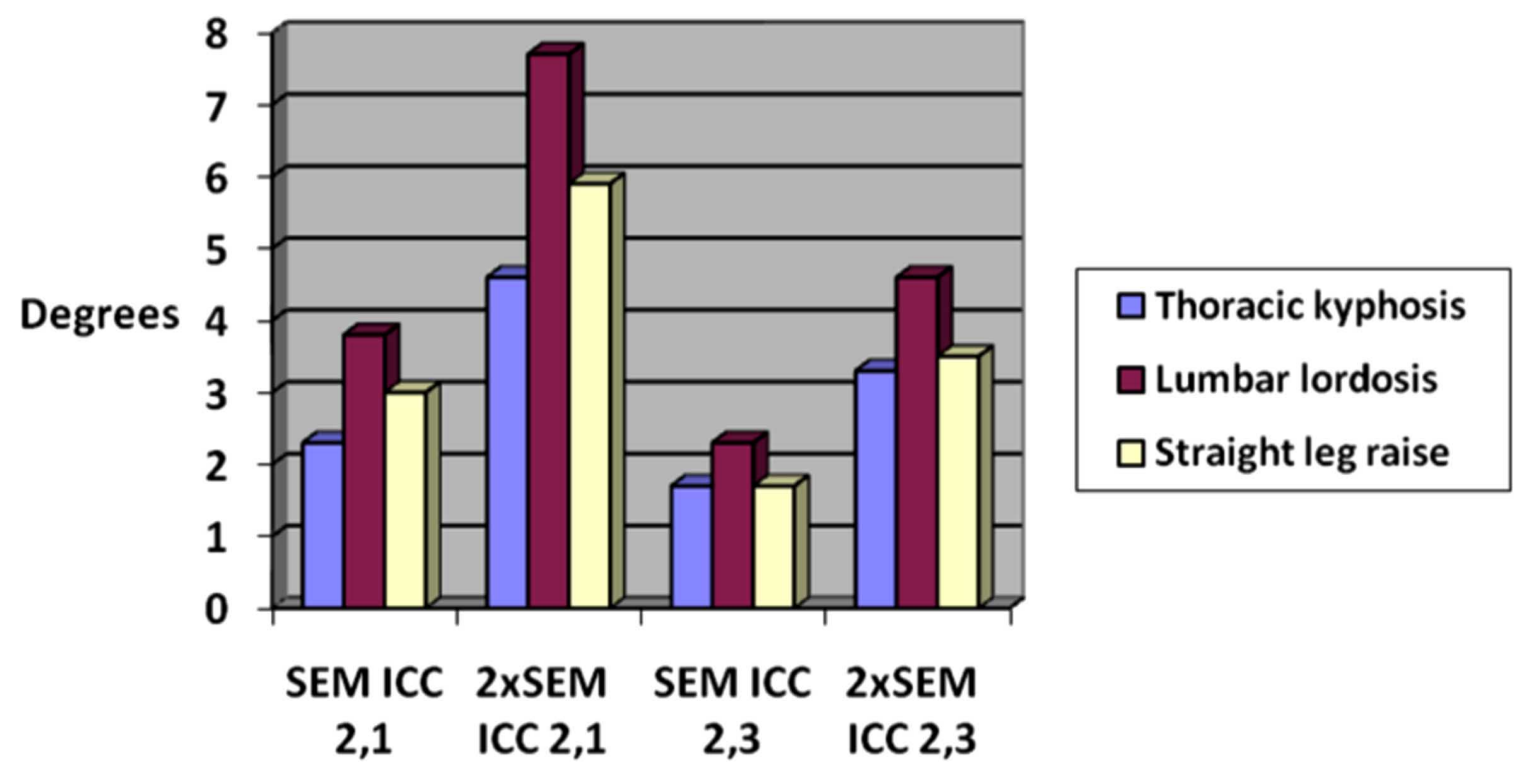

Fig. (3). SEM and 2xSEM values.

from 0.79 to 0.94 , and for average measures [ICC Model $(2,3)]$ ranged from 0.93 to 0.98 .

Thoracic kyphosis, lumbar lordosis and SLR measures all showed ICC's > 0.75 for ICC $(2,1)$ and $\operatorname{ICC}(2,3)$ measurements, thus indicating good overall reliability [19]. The ICC average measures $(2,3)$ demonstrated agreement above 0.90 for all three variables. Most notably, SLR demonstrated the best ICC out of all measures with 0.94 for the single ICC $(2,1)$ and 0.98 for the average $\operatorname{ICC}(2,3)$ measures. In addition, thoracic kyphosis and lumbar lordosis angle scored highly using the standards of agreement described by Portney \& Watkins [19], with average measure ICC's equating to 0.94 and 0.93 , respectively. For the average measures, the $95 \%$ CI for SLR, thoracic kyphosis and lumbar lordosis (Table 2) all show relatively narrow boundaries indicating a small margin of error in the application of this technique [24].

The SEM, a reflection of the degree of error associated with a particular method of measurement [19], demonstrated 1 SEM values of $2^{\circ}$ for thoracic kyphosis, lumbar lordosis and the SLR Fig. (3). Using the 1 SEM, a clinician may assume with $68 \%$ certainty that the individuals true score will lie between $+/-2^{\circ}$ of the measured value if the clinician's skill matches the examiner in this study. When examining the 2 SEM scores, which increase the certainty to $95 \%$, these values increase to approximately $4^{\circ}$. Therefore, the minimal value required for these measures to be considered real change is $4^{\circ}$.

\section{DISCUSSION}

The primary focus of this study was to evaluate the intrarater reliability of clinical methods for measuring thoracic kyphosis, lumbar lordosis and SLR. Analysis of the results obtained in this study suggest that the technique employed by the chief investigator demonstrated reliability acceptable for clinical application [19].

At present, a limited number of investigations have assessed the intra-rater reliability of thoracic kyphosis, lumbar lordosis or SLR. Furthermore, no studies have been identified that assess a single investigator's reliability when measuring all three variables as part of a continuous assessment procedure that replicates clinical practice. In order to validate the external measurement techniques undertaken in this study, comparisons have been made between results of this investigation and those found in the literature.

\section{THORACIC KYPHOSIS}

As part of a larger investigation examining shoulder impingement syndrome, Lewis and colleagues [10] performed a pilot study to test the measurement reliability of the chief investigator. In the asymptomatic group, Lewis $e t$ al. [10] demonstrated single measurement ICC $(2,1)$ scores for thoracic kyphosis of $0.96,95 \%$ CI from $0.91-0.98$, and $+/-1$ SEM of $2^{\circ}$. These results are in strong agreement with those of the current study which demonstrated good reliability for both single $[\operatorname{ICC}(2,1)=0.92 ; 95 \% \mathrm{CI}=0.84-$ 0.96 ; and 1 SEM $=2^{\circ}$ ] and average $[\operatorname{ICC}(2,3)=0.96 ; 95 \%$ $\mathrm{CI}=0.92-0.98$; and $\left.1 \mathrm{SEM}=2^{\circ}\right]$ measures. Although 30 subjects were tested by Lewis et al. [10], the symptomatic (n $=15)$ and asymptomatic $(n=15)$ groups were examined independently. It has been suggested that 19 subjects would be adequate to determine true instrument reliability [21]. For this reason, subject numbers used in the Lewis et al. investigation [10] may not have been sufficient in comparison to the larger sample size used in the current study.

In addition to the Lewis et al. [10] findings, Mellin [11] demonstrated similar intra-rater ICC values of 0.92 when measuring the kyphosis of asymptomatic subjects $(n=10)$. Unfortunately, this author does not describe in detail which mathematical method was used to calculate the thoracic angle, thus making it difficult for comparisons to be made with the current investigation. In accordance with Sim and Wright's [22] suggested subject sample size of 19, the ten subjects in Mellin's study may not have been sufficient to fully determine the reliability of the technique. However, even with this reduced sample size, similar ICC values to that of our larger study were obtained. 


\section{LUMBAR LORDOSIS}

Mellin [11] reported similar ICC values (0.94) to the current study for postural lordosis, however, there is no reference to the ICC model that was used. Agreement between these two findings may relate to similar subject positioning as both studies measured spinal curvatures in neutral standing. In a more recent study, $\mathrm{Ng}$ et al. [15] measured lumbar angles in combination with lumbar range of movement on 12 healthy men with no history of back pain. The ICC results for lumbar lordosis were 0.95, suggesting that the method of measurement employed by $\mathrm{Ng}$ and colleagues [15] showed adequate clinical reliability [19]. However, even though their score is similar to that achieved in the present study, it should not be construed as a definitive clinical representation of reliability. These authors did not calculate the $95 \%$ CI or SEM, which help to indicate the magnitude of disagreement between measurements, or indicate which ICC model was used for analysis.

The results of the present study also lend support to the findings of Norton et al. [25] who measured the lumbar curvature of 30 adults using the Metrecom and a bubble goniometer. Norton et al. [25] demonstrated an $\operatorname{ICC}(3,3)$ of 0.92 . Similarities in the ICC scores are thought to be due to a number of reasons. Firstly, the methods employed in both investigations utilise the tangent mathematical model as described by Loebl [12]. Secondly, both Norton et al. [25] and the investigators in the current study recorded lumbar lordosis from the spinous processes of T12/L1 and S2.

\section{SLR}

Excellent intra-rater reliability $[\operatorname{ICC}(2,3)=0.98 ; 95 \%$ CI $=0.96-0.99$; and $\left.2 \mathrm{SEM}=4^{\circ}\right]$ was shown in the current investigation when measuring SLR. These findings are comparable with those shown in one previous study by Li et al. [26] who demonstrated an ICC of 0.99 when using an inclinometer to record SLR using a similar method. Conversely, inclinometer readings for a SLR reliability pilot study by Corben et al. [17] showed good levels of reliability with an ICC of $0.87,95 \%$ CI of $0.56-0.97$, and SEM of $3^{\circ}$ [17]. Of particular interest is that both Corben et al. [17], and the investigators in the current study measured SLR with the Isomed inclinometer placed over the tibial tuberosity of the testing leg. However, despite similarities in the testing procedure, reliability results were considerably different. This can be attributed to a number of factors. Firstly, when testing SLR the present study fixed the thigh of the nontested leg to the bed using a second examiner. Another possible reason for the differences in findings was that Corben et al. [17] rested the opposite limb on pillows which may have reduced the specificity of the test. Additionally, these investigators used a small sample size $(n=10)$ to examine SLR reliability.

\section{LIMITATIONS}

Postural variation resulting from respiration and postural sway may have led to a degree of error during the measurement procedure. In addition, potential inaccuracies on palpation of anatomical landmarks may have affected the validity of the measurement. Subjects included in this study were 30 asymptomatic adults. Therefore, generalization of these results to individuals who are older or symptomatic would not be appropriate.

\section{CLINICAL IMPLICATIONS}

Current methods of measurements for idiopathic scoliosis include radiographic and stereovideographic techniques which can be both expensive and time consuming [27]. Therefore, the use of a simple, quick and reliable method for quantifying modifications in postural geometry would be valuable to clinicians who assess patients presenting with conditions like Ankylosing Spondylitis and Scheuermann's disease. The values obtained from the spinal measurements described in this study could also be used by clinicians providing feedback to patients when educating them on good postural positioning. Although this study demonstrates high reliability for the inclinometer assessment techniques, it does not demonstrate their validity as measures of spinal curvature. In order to establish validity, further research, comparing spinal angles obtained from inclinometer assessment with those obtained from radiographic investigations - the gold standard - is required.

\section{CONCLUSION}

The methods employed in this study have demonstrated excellent clinical reliability (ICC > 0.90) whilst using an Isomed inclinometer to measure thoracic kyphosis, lumbar lordosis and SLR in asymptomatic subjects. Advantages associated with this reliable method of measurement are that it is simple to use, time efficient, and relatively inexpensive to maintain. These positive characteristics lend further support to the use of this instrument within clinical practice, and should give therapists confidence when using this method of measurement to help guide treatment progression. The findings of this study compare favourably with previous studies, especially as this was one of the first investigations to utilise both a larger sample size and appropriate reliability statistical analyses.

\section{CONFLICT OF INTEREST}

The authors confirm that this article content has no conflicts of interest.

\section{ACKNOWLEDGEMENT}

Declared none.

\section{REFERENCES}

[1] Sahrmann SA. Diagnosis and Treatment of Movement Impairment Syndromes. Missouri: Mosby Inc 2002.

[2] Kuo Y, Tully EA, Galea MP. Sagittal spinal posture after pilatesbased exercise in healthy older adults. Spine 2009; 34: 1046-51.

[3] Kendall FP, McCreary EK, Provance PG, et al. Muscles, Testing and Function with Posture and Pain. $5^{\text {th }}$ ed. London: Lippincott Williams \& Wilkins 2005.

[4] O'Sullivan PB. 'Clinical instability' of the lumbar spine: its pathological basis, diagnosis and conservative management. In: Boyling J, Jull G, Eds. Grieve's Modern Manual Therapy. $3^{\text {rd }}$ ed. Singapore: Churchill Livingstone 2004.

[5] Smith A, O'Sullivan P, Straker L. Classification of sagittal thoracolumbo pelvic alignment of the adolescent spine in standing and its relationship to low back pain. Spine 2008; 33: 2101-7.

[6] Majlesi J, Togay H, Unalan H, et al. The sensitivity and specificity of the Slump and the Straight Leg Raising tests in patients with lumbar disc herniation. J Clin Rheumatol 2008; 14: 87-91. 
[7] Shacklock M. Improving application of neurodynamic (neural tension) testing and treatments: A message to researchers and clinicians. Man Ther 2005; 10: 175-9.

[8] Goh S, Price RI, Leedman PJ, Singer KP. A comparison of three methods for measuring thoracic kyphosis: implications for clinical studies. Rheum (Oxford) 2000; 39(3): 310-5.

[9] Briggs AM, Wrigley TV, Tully EA, Adams PE, Greig AM, Bennell KL. Radiographic measures of thoracic kyphosis in osteoporosis: Cobb and vertebral centroid angles. Skeletal Radiol 2007; 36(8): 761-7.

[10] Lewis JS, Green A, Wright C. Subacromial impingement syndrome: The role of posture and muscle imbalance. J Shoulder Elbow Surg 2005; 14: 385-92.

[11] Mellin G. Measurement of thoracolumbar posture and mobility with a Myrin Inclinometer. Spine 1986; 11: 759-62.

[12] Loebl WY. Measurement of spinal posture and range of spinal movement. Ann Phys Med 1967; 9: 103-10.

[13] O'Gorman H, Jull GA. Thoracic kyphosis and mobility: the effect of age. Physiother Theory Pract 1987; 3: 154-62.

[14] Crawford HJ, Jull GA. The influence of thoracic posture and movement on range of arm elevation. Physiother Theory Pract 1993; 9: 143-8.

[15] Ng JKF, Kippers V, Richardson CA. Range of motion and lordosis of the lumbar spine: reliability of measurement and normative values. Spine 2001; 26: 53-60.

[16] Hunt DG, Zuberbier OA, Kozlowski AJ, et al. Reliability of the lumbar flexion, lumbar extension and passive straight leg raise test in normal populations embedded within a complete physical examination. Spine 2001; 26: 2714-8.
[17] Corben T, Lewis JS, Petty, NJ. Contribution of lumbar spine and hip movement during the palms to floor test in individuals with diagnosed hypermobility syndrome. Physiother Theory Pract 2008; 24: 1-12.

[18] Ekstrand J, Wiktorsson M, Oberg B, et al. Lower extremity goniometric measurements: a study to determine their reliability. Arch Phys Med Rehabil 1982; 63: 171-5.

[19] Portney L, Watkins MP. Gross Foundations of clinical research: applications to practice. $3^{\text {rd }}$ ed. New Jersey: Pearson Education 2009.

[20] Palastanga N, Field D, Soames R. Anatomy and Human Movement: Structure and Function. $4^{\text {th }}$ ed. London: ButterworthHeinemann 2002.

[21] Walter SD, Eliasziw M, Donner A. Sample size and optimal designs for reliability studies. Stat Med 1998; 17: 101-10.

[22] Sim J, Wright C. Research in health care: concepts, designs and methods. Cheltenham: Stanley Thornes (Publishers) Ltd 2000.

[23] Hicks C. Research Methods for Clinical Therapists: applied project design and analysis. $4^{\text {th }}$ ed. Edinburgh: Churchill Livingstone 2004.

[24] Field A. Discovering Statistics Using SPSS. $2^{\text {nd }}$ ed. London: Sage Publications 2005.

[25] Norton BJ, Hensler K, Zou D. Comparisons among non-invasive methods for measuring lumbar curvature in standing. J Orthop Sports Phys Ther 2002; 32: 405-14.

[26] Li Y, McClure PW, Pratt N. The effect of hamstring muscle stretching on standing posture and on lumbar and hip motions during forward bending. Phys Ther 1996; 76: 836-49.

[27] Leroux MA, Zabjek K, Simard G, et al. A non-invasive anthropometric technique for measuring kyphosis and lordosis. Spine 2000; 25: 1689-94.

\section{Received: March 09, 2012 \\ (C) Blommestein et al.; Licensee Bentham Open.}

Revised: May 19, 2012

Accepted: May 22, 2012

This is an open access article licensed under the terms of the Creative Commons Attribution Non-Commercial License (http://creativecommons.org/licenses/by$\mathrm{nc} / 3.0 /$ ), which permits unrestricted, non-commercial use, distribution and reproduction in any medium, provided the work is properly cited. 